Revista Brasileira de Agricultura Irrigada v.13, no.4, p. 3498 - 3511, 2019

ISSN 1982-7679 (On-line)

Fortaleza, CE, INOVAGRI - http://www.inovagri.org.br

DOI: $10.7127 /$ rbai.v13n4001003

Protocolo 1003.19 - 02/08/2018 Aprovado em 26/07/2019

\title{
ALFACE SUBMETIDA À ADUBAÇÃO NITROGENADA E TENSÕES DE ÁGUA NO SOLO EM AMBIENTE PROTEGIDO
}

\author{
Kassio dos Santos Carvalho ${ }^{1}$, Marcio Koetz ${ }^{2}$, Edna Maria Bonfim da Silva ${ }^{2}$, Tonny José Araújo da \\ Silva $^{2}$, Carlos Eduardo Avelino Cabral ${ }^{2}$
}

\section{RESUMO}

A alface é uma cultura exigente em água, sendo o manejo adequado da irrigação importante, assim como a adubação nitrogenada, pois é ela que estimula o desenvolvimento da planta. Objetivou-se avaliar o efeito entre tensões de água no solo e níveis de adubação nitrogenada no desenvolvimento da alface americana. O experimento foi conduzido em casa de vegetação e o delineamento experimental foi inteiramente casualizado, em esquema fatorial $4 \times 5$, sendo quatro níveis de tensão de água no solo $(15,30,45$ e $60 \mathrm{kPa})$ e cinco níveis de adubação nitrogenada $(0,50,100,150$ e $200 \mathrm{mg}$ $\left.\mathrm{dm}^{-3}\right)$, totalizando 20 tratamentos, com quatro repetições. A fonte de nitrogênio usada foi à ureia e as tensões foram controladas por tensiômetros instalados a $10 \mathrm{~cm}$ de profundidade nas unidades experimentais adubadas com $100 \mathrm{mg} \mathrm{dm}^{-3}$ de nitrogênio. Na ausência de adubação nitrogenada e maior déficit hídrico, ocorreu maior produção de massa seca de raiz. O nitrogênio influenciou as variáveis analisadas, sendo que o intervalo de adubação nitrogenada deve ficar entre 136,66 e 168,72 $\mathrm{kg} \mathrm{ha}^{-1}$ para que a cultura apresente seu maior desempenho agronômico e o solo mantido na tensão de $15 \mathrm{kPa}$.

Palavras-chave: Lactuca sativa L., nutrição de planta, tensiômetro.

\section{LETTUCE SUBMITTED TO NITROGEN FERTILIZATION AND SOIL WATER TENSION IN ENVIRONMENT PROTECTED}

\begin{abstract}
Lettuce is a culture demanding in water consumption and the adequate irrigation management is major, as well as nitrogen fertilization because it stimulates the development of the plant . This study aimed to evaluate the effect of soil water tensions and nitrogen levels in the development of

\footnotetext{
${ }^{1}$ Docente, Instituto Federal de Educação de Mato Grosso/IFMT, Sorriso, MT, Av. dos Universitários, n. 799, Barro Santa Clara, Cep: 78890-000, email: kassio.carvalho@srs.ifmt.edu.br

${ }^{2}$ Docente, Instituto de Ciências Agrárias e Tecnológicas/UFMT, Rondonópolis, MT, Av. dos estudantes, n. 5055, Bairro Sagrada Família, Cep: 78735-901, e-mails: marciokoetz@yahoo.com.br; embonfim@hotmail.com; tonny.silva@pq.cnpq.br e carlos.eduardocabral@hotmail.com
} 
American lettuce. The experiment was conducted in a greenhouse and the experimental design was completely randomized, in a $4 \times 5$ factorial scheme, with four water tension levels in the soil $(15,30$, 45 and $60 \mathrm{kPa}$ ) and five levels of nitrogen fertilization $\left(0,50,100,150\right.$ and $\left.200 \mathrm{mg} \mathrm{dm}^{-3}\right)$, totaling 20 treatments, with four replications. The nitrogen source used to urea and tensions were controlled by tensiometers installed at $10 \mathrm{~cm}$ depth in the experimental units fertilized with $100 \mathrm{mg} \mathrm{dm}^{-3}$ nitrogen. In the absence of nitrogen fertilization and higher water deficit, there was a higher production of dry mass root. The nitrogen fertilization should be between 136.66 and $168.72 \mathrm{~kg} \mathrm{ha}^{-1}$ for a crop to present its highest agronomic performance and soil maintained at $15 \mathrm{kPa}$.

Keywords: Lactuca sativa L., plant nutrition, tensiometers.

\section{INTRODUÇÃO}

A alface é uma cultura exigente em água, sendo a irrigação importante não apenas por suprir a necessidade hídrica da planta, mas também por minimizar problemas com doenças, lixiviação de nutrientes e gastos desnecessários com água e energia (KOETZ et al., 2006).

Dentre os sensores de monitoramento da umidade do solo, o tensiômetro se destacada, devido ao baixo custo, a facilidade operacional e pouca manutenção. Para que ocorra o sucesso operacional dessa tecnologia é necessária à determinação da tensão de água no solo ideal para acionar o sistema de irrigação, pois esta varia de acordo com a cultura cultivada.

$\mathrm{O}$ cultivo em ambiente protegido permite melhorar a qualidade e a produtividade, além de ofertar ao mercado um produto que em condições de campo não seria possível. Nesses ambientes a irrigação é imprescindível e fornecer água à cultura no momento certo e em quantidade certa pode viabilizar o processo produtivo (CARVALHO et al., 2011).

Mesmo sendo importante o cultivo em ambiente protegido para a olericultura brasileira, ainda são insuficientes os resultados de pesquisa que subsidiem o aproveitamento dessa tecnologia nas diferentes regiões do país, notadamente aqueles necessários ao adequado manejo da irrigação. Nesse aspecto, há necessidade de serem quantificados, dentre outros, os efeitos dos fatores microclimáticos sobre a evapotranspiração da cultura e os níveis de tensão de água do solo capazes de promover uma produtividade ótima (SANTOS; PEREIRA, 2004).

Outro fator que contribui com o desempenho agronômico da alface é a adubação nitrogenada, segundo (Resende et al., , 2010) a recomendação para a alface encontra-se em torno de $90 \mathrm{~kg} \mathrm{ha}^{-1}$. Entretanto, existe a necessidade de pesquisas com doses de adubação nitrogenada para a região de Cerrado, que apresenta temperaturas elevadas durante todo o ano e ciclo de crescimento da cultura nenor, e ainda, obtenção de resultados em casa de vegetão.

Assim, objetivou-se avaliar o efeito entre tensões de água no solo e níveis de adubação nitrogenada, no desenvolvimento da alface americana, cultivada em ambiente protegido.

\section{MATERIAIS E MÉTODOS}

O experimento foi conduzido em casa de vegetação do programa de Pós Graduação em Engenharia Agrícola do Campus Universitário de Rondonópolis -UFMT, de outubro de 2012 a março de 2013 , situado $16^{\circ} 27^{\prime} \mathrm{S}$ e $54^{\circ} 34^{\prime}$ $\mathrm{O}$, a uma altitude de 282 metros. No interior da casa de vegetação foi instalado um termohigrômetro para determinação da temperatura e umidade, máxima e mínima, cujas leituras dos dados eram realizadas diariamente, durante 29 dias, desde o transplantio das mudas até a colheita. A temperatura média do ar durante o período de condução do experimento foi de $32,8^{\circ} \mathrm{C}$, sendo que as temperaturas médias mínimas e máximas foram de 25,1 e $39,9{ }^{\circ} \mathrm{C}$, respectivamente, com oscilação entre 20,0 e 
43,3 ${ }^{\circ} \mathrm{C}$ (Figura 1 A). Enquanto a umidade relativa média foi de $69,2 \%$, a mínima de $53,6 \%$ e a média da umidade relativa máxima foi $84,8 \%$, com oscilação entre 37 e $99 \%$ (Figura $1 \mathrm{~B}$ ).
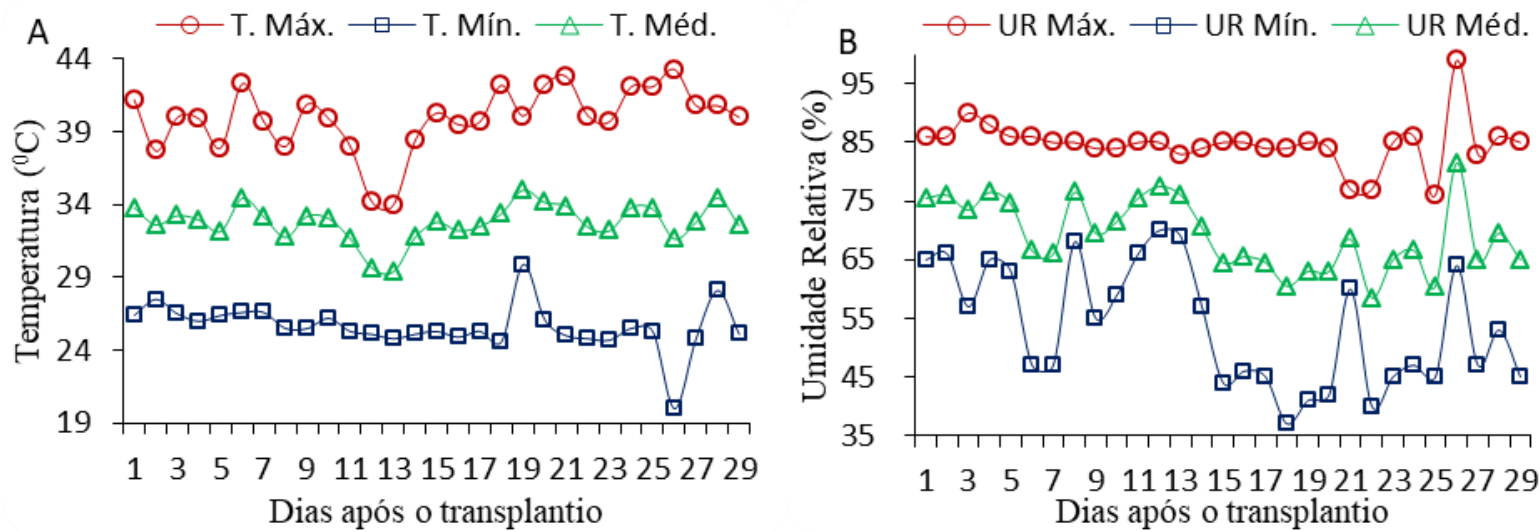

Figura 1. Temperatura $\left({ }^{\circ} \mathrm{C}\right)$ mínima, média e máxima do ar $(\mathrm{A})$ e umidade relativa $(\%)$ mínima, média e máxima do ar (B) no interior da casa de vegetação, no período de 29 de janeiro a 26 de fevereiro de 2013 em Rondonópolis - Mato Grosso.

O solo utilizado foi o Latossolo Vermelho, cuja caracterização química e granulométrica é apresentada na Tabela 1, que foi coletado em área sob vegetação de Cerrado na profundidade de 0 a $20 \mathrm{~cm}$ e peneirado em malha de $4 \mathrm{~mm}$, sendo posteriormente incubado com calcário dolomítico (PRNT = $80,3 \%$ ), elevando-se a saturação por bases para $70 \%$.

Tabela 1. Caracterização química e granulométrica do Latossolo Vermelho do Cerrado utilizado no cultivo da alface 'Rafaela'.

\begin{tabular}{|c|c|c|c|c|c|c|c|c|c|c|c|c|c|}
\hline $\mathrm{pH}$ & $\mathrm{P}$ & $\mathrm{K}$ & $\mathrm{Ca}$ & $\mathrm{Mg}$ & $\mathrm{Al}$ & $\mathrm{H}$ & CTC & MO & V & $\mathrm{m}$ & Areia & Silte & Argila \\
\hline $\mathrm{CaCl}_{2}^{+}$ & \multicolumn{2}{|c|}{$--\mathrm{mg} \mathrm{dm}^{-3}--$} & \multicolumn{5}{|c|}{------ cmolc dm dm $^{-3}$} & $\mathrm{~g} \mathrm{~kg}^{-1}$ & \multicolumn{2}{|c|}{---- \% --- } & \multicolumn{3}{|c|}{------- $\mathrm{g} \mathrm{kg}^{-1}$------- } \\
\hline 4,1 & 1,1 & 47,0 & 0,2 & 0,1 & 1,0 & 4,7 & 6,1 & 19,7 & 6,9 & 70,4 & 575,0 & 50,0 & 375,0 \\
\hline
\end{tabular}

Potencial Hidrogeniônico $(\mathrm{pH})$, Cloreto de Cálcio $\left(\mathrm{CaCl}_{2}{ }^{+}\right)$, Fósforo $(\mathrm{P})$, Potássio $(\mathrm{K})$, Cálcio $(\mathrm{Ca})$, Magnésio $(\mathrm{Mg})$, Hidrogênio (H), Alumínio (Al), Capacidade de Troca de Cátions (CTC), Saturação por Base (V) e Matéria Orgânica (M.O).

O delineamento experimental utilizado foi inteiramente casualizado, em esquema fatorial $4 \times 5$, correspondendo a quatro tensões de água no solo $(15,30,45$, e $60 \mathrm{kPa})$ e cinco níveis de nitrogênio $(0,50,100,150$ e $200 \mathrm{mg}$ $\mathrm{dm}^{-3}$ ) com quatro repetições, totalizando 80 unidades experimentais. A fonte de nitrogênio utilizada foi à ureia. Cada parcela experimental foi constituída por um vaso com capacidade para $7 \mathrm{dm}^{3}$ de solo e com uma planta.

A semeadura da alface cultivar 'Rafaela' foi realizada em bandejas de 24 células, preenchidas com substrato comercial com fibra de coco próprio para hortaliças. Aos 23 dias após a semeadura, quando as mudas apresentaram 5 folhas, foi realizado o transplantio de 3 mudas por unidade experimental. Cinco dias após o transplantio foi realizado o desbaste, deixando-se uma planta por vaso. Manteve-se o solo na capacidade de campo até o $13^{\circ}$ dia após o transplantio, onde se deu início aos tratamentos com as lâminas de irrigação.

Após 95 dias de incubação do calcário, foi realizado a adubação com as seguintes doses, em $\mathrm{mg} \mathrm{dm}^{-3}: \mathrm{P}=300, \mathrm{~K}=100, \mathrm{~B}=$ 0,75 , e $\mathrm{Zn}=2,25$, nos quais as fontes foram, superfosfato simples, cloreto de potássio, ácido bórico e sulfato de zinco, 
Carvalho et al.

respectivamente. A aplicação foi realizada por meio de solução, assim como para os tratamentos com adubação nitrogenada, divididas em quatro aplicações, com intervalos de três a quatro dias entre uma aplicação e outra, exceto para o fósforo que foi incorporado ao solo três dias antes do transplantio.

Durante todo o período experimental a umidade do solo foi monitorada por tensiômetros, instalados a $0,10 \mathrm{~m}$ de profundidade nos tratamentos de $15,30,45 \mathrm{e}$

$$
\theta a=\theta r \frac{\theta s-\theta r}{\left[1+(\alpha \times \Psi)^{n}\right]^{m}}
$$

Em que: $\theta \mathrm{a}, \theta \mathrm{r}$ e $\theta \mathrm{s}$ - umidade atual, residual e de saturação, respectivamente $\left(\mathrm{cm}^{3} \mathrm{~cm}^{-3}\right) ; \Psi$ -
$60 \mathrm{kPa}$ e $100 \mathrm{mg} \mathrm{dm}^{-3}$ de nitrogênio (dose de referência). As leituras fornecidas pelo tensiômetro foram utilizadas na equação de Van Genuchten (1980), descrita na equação 1, para encontrar a umidade atual do solo. A curva característica de água no solo apresentada na Figura 2 foi determinada em laboratório, por meio da câmera de Richards com auxílio do software Soil Water Retention Curve (versão 3.0), (DOURADO NETO et al., 2000). tensão de água no solo (cm); $\alpha, \mathrm{m}$ e $\mathrm{n}$ coeficientes gerados pelo modelo.

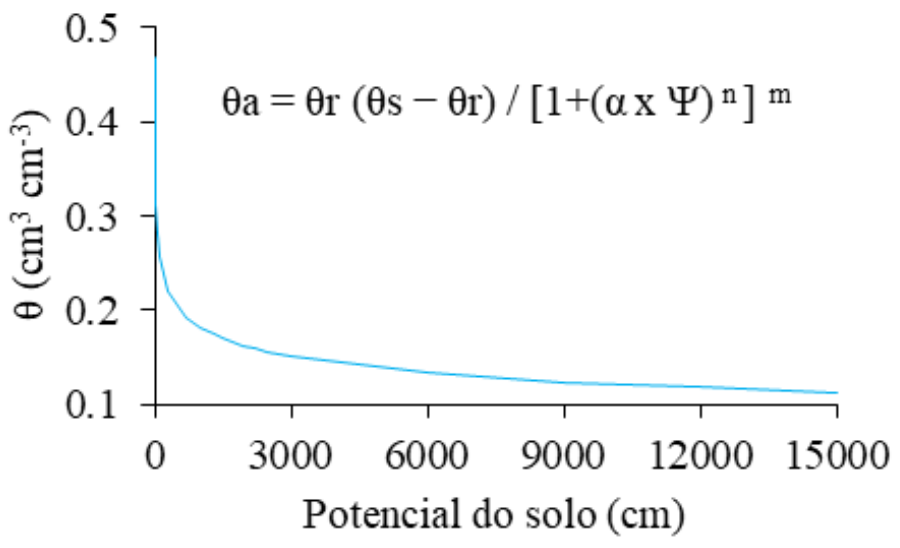

Figura 2. Curva de retenção de água no solo, gerada pelo programa Soil Water Retention Curve (versão 3.0) e a equação da umidade do solo (DOURADO NETO et al., 2000).

A umidade na capacidade de campo $(\theta \mathrm{cc})$ adotada foi de $5 \mathrm{kPa}$ e com a umidade atual $(\theta a)$ para as tensões obtidas nos tensiômetros no momento da leitura, calculou-

$$
V o l=(\theta c c-\theta a) \times 7.000,
$$

Em que: $\theta$ cc - umidade na capacidade de campo $\left(\mathrm{cm}^{3} \mathrm{~cm}^{-3}\right) ; \theta \mathrm{a}$ - umidade atual do solo $\left(\mathrm{cm}^{3} \mathrm{~cm}^{-3}\right)$; Vol - volume de água $\left(\mathrm{cm}^{3}\right)$.

$\mathrm{O}$ tratamento com a tensão de água no solo pré-estabelecida de $15 \mathrm{kPa}$ recebeu o maior número de irrigações e também o maior volume de água aplicado (Tabela 2), seguido pelo tratamento de 30, 45 e $60 \mathrm{kPa}$, respectivamente. $\mathrm{O}$ intervalo médio entre as se o volume de água necessário para elevar o solo à capacidade de campo de acordo com a equação 2 . 
Tabela 2. Médias do consumo de água, número de irrigações e intervalo entre as irrigações para as tensões de água no solo pré-estabelecidas no cultivo da alface 'Rafaela'.

\begin{tabular}{|c|c|c|c|c|}
\hline $\begin{array}{c}\text { Tensão pré- } \\
\text { estabelecida (kPa) }\end{array}$ & $\begin{array}{l}\text { Consumo de } \\
\text { água }(\mathrm{ml})\end{array}$ & $\begin{array}{l}\text { Consumo de } \\
\text { água }(\mathrm{mm})\end{array}$ & $\begin{array}{l}\text { Número de } \\
\text { irrigações }\end{array}$ & $\begin{array}{l}\text { Intervalo médio entre } \\
\text { irrigações (dias) }\end{array}$ \\
\hline 15 & 4084 & 66,36 & 15 & 1,0 \\
\hline 30 & 3505 & 56,95 & 8 & 1,9 \\
\hline 45 & 2749 & 44,67 & 5 & 3,0 \\
\hline 60 & 2728 & 44,32 & 4 & 3,8 \\
\hline $\begin{array}{l}\text { A colheita } \\
\text { plantas apresentar } \\
\text { vegetativo apto a se } \\
\text { se deu aos } 28 \text { dias a } \\
\text { que as variáveis a } \\
\text { fresca da parte aérea } \\
\text { área foliar, massa se } \\
\text { das raízes. Para se } \\
\text { folhas, estas foram } \\
\text { contadas. A massa f } \\
\text { foi obtida com a pe }\end{array}$ & $\begin{array}{l}\text { realizada qu } \\
\text { um des } \\
\text { n comercializ: } \\
\text { s o transplant } \\
\text { lisadas foram } \\
\text { otal, número c } \\
\text { da parte aére } \\
\text { terminar o nu } \\
\text { emovidas do } \\
\text { ca da parte a }\end{array}$ & $\begin{array}{l}\text { do as } \\
\text { penho } \\
\text { s, que } \\
\text { sendo } \\
\text { massa } \\
\text { olhas, } \\
\text { otal e } \\
\text { ro de } \\
\text { tule e } \\
\text { a total } \\
\text { semi }\end{array}$ & \multicolumn{2}{|c|}{$\begin{array}{l}\text { método de Huerta (1962), tendo-se o auxílio } \\
\text { de um cilindro com área conhecida }\left(2,14 \mathrm{~cm}^{2}\right) \text {, } \\
\text { o qual foi utilizado para remover três discos } \\
\text { das folhas por parcela. Após a retirada dos } \\
\text { discos foi efetuado a pesagem e de posse do } \\
\text { peso total dos três discos e da massa fresca } \\
\text { total, realizou-se uma relação entre a massa } \\
\text { fresca total e a massa dos discos (com área } \\
\text { conhecida), obtendo assim a área foliar em } \\
\mathrm{cm}^{2} \text { (equação 3): }\end{array}$} \\
\hline
\end{tabular}
analítica e os resultados foram expressos em gramas.

$$
A F=\frac{(M F F \times(2,14 \times 3))}{M F D},
$$

Em que: MFF - Massa fresca das folhas; MFD - Massa fresca de parte das folhas (disco).

Para determinar a massa seca da parte aérea total e das raízes, estas foram colocadas em sacos de papel e levadas a estufa de circulação de ar forçada à temperatura de $65^{\circ} \mathrm{C}$, até atingir massa constante, obtendo os resultados em gramas. As raízes foram peneiradas em malha de $4 \mathrm{~mm}$ e lavadas para só então, serem colocadas em sacos de papel e levadas à estufa.

Os dados coletados e após a tabulação foram submetidos à análise a variância com a realização do teste $\mathrm{F}$ e posteriormente a regressão, ambas a $5 \%$ de significância, por meio do programa estatístico SISVAR 5.3 (FERREIRA, 2011).

\section{RESULTADOS E DISCUSSÃO}

A análise de variância para as características fitométricas e produtivas da alface em função das tensões de água no solo, apresentaram diferença pelo teste de $\mathrm{F}$, sendo que as variáveis NF, MFTOL, AF e MSTOL a $(\mathrm{p}<0,01)$ e a variável MSR não apresentou efeito isolado ao nível de $(\mathrm{p}<0,05)$ (Tabela 3$)$. Quando se avalia o efeito da adubação nitrogenada, verifica-se que as variáveis MSR, AF e MSTOL apresentaram efeito ao nível de $(\mathrm{p}<0,01)$ e efeito a $(\mathrm{p}<0,05)$ para MFTOL e não apresentou efeito sobre o NF (Tabela 3). 
Carvalho et al.

Tabela 3. Resumo da análise de variância com quadrados médios e coeficientes de variação (CV \%) para número de folhas (NF), massa fresca da parte aérea total (MFTOL), área foliar (AF), massa seca de raiz (MSR), massa seca da parte aérea total (MSTOL), da cultura da alface cultivar "Rafaela" em resposta à adubação nitrogenada e às tensões de água no solo.

\begin{tabular}{ccccccc}
\hline \multirow{2}{*}{$\begin{array}{c}\text { Fonte de } \\
\text { variação }\end{array}$} & GL & NF & $\begin{array}{c}\text { MFTOL } \\
\text { g planta }^{-1}\end{array}$ & $\begin{array}{c}\text { AF } \\
\mathrm{cm}^{2}\end{array}$ & $\begin{array}{c}\text { MSR } \\
\text { g planta }^{-1}\end{array}$ & $\begin{array}{c}\text { MSTOL } \\
\text { g planta }^{-1}\end{array}$ \\
\hline Tensão (T) & 3 & $83,45^{* *}$ & $31572,88^{* *}$ & $1939358,07^{* *}$ & $2,22^{\text {ns }}$ & $86,46^{* *}$ \\
Nitrogênio (N) & 4 & $0,931^{\text {ns }}$ & $34440,46^{*}$ & $646505,53^{* *}$ & $4,01^{* *}$ & $38,71^{* *}$ \\
N x T & 12 & $6,76^{\text {ns }}$ & $2106,31^{*}$ & $90749,01^{\text {ns }}$ & $3,89^{* *}$ & $10,52^{* *}$ \\
Resíduo & 60 & 2,95 & 1081,42 & 50302,33 & 0,97 & 2,12 \\
Média & - & 17,44 & 176,73 & 1327,17 & 3,32 & 11,36 \\
C.V. (\%) & - & 9,86 & 18,61 & 16,9 & 29,63 & 12,82 \\
\hline
\end{tabular}

${ }^{\text {ns }}$, não significativo. ${ }^{*} \mathrm{e}^{* *}$ significativo a 5 e $1 \%$ de significância, pelo teste de $\mathrm{F}$, respectivamente.

O NF não apresentou resposta à adubação nitrogenada, isso pode ter ocorrido devido o nitrogênio não influenciar fortemente essa variável, principalmente no início do ciclo da cultura (MARTINS et al., 2009), sendo ela controlada pelas características genética da cultivar. Nascimento et al. (2017) trabalhando com a cultura do repolho também não encontraram resposta à adubação nitrogenada, para essa variável.

Para o NF, independente do nível de adubação nitrogenada, à medida que se aumentou a tensão de água no solo de $15 \mathrm{kPa}$ até $60 \mathrm{kPa}$, reduziu-se no $\mathrm{NF}$ em $22,6 \%$ (Figura 3). Santos e Pereira (2004), também observaram resultados semelhante no cultivo de alface, cv. "Raider", em estufa, encontraram o máximo de 22,25 folhas para a tensão de $15 \mathrm{kPa}$, e no presente estudo, para a tensão de água no solo de $15 \mathrm{kPa}(19,50$ folhas).

Essa redução no número de folhas pode ter ocorrido em função da quantidade de água disponível no solo para as plantas, pois são dependentes, porquanto o déficit hídrico provoca o fechamento dos estômatos, diminuindo a assimilação de $\mathrm{CO}_{2}$ e as atividades fisiológicas das plantas, principalmente a divisão e o crescimento das células (REGO et al., 2004).

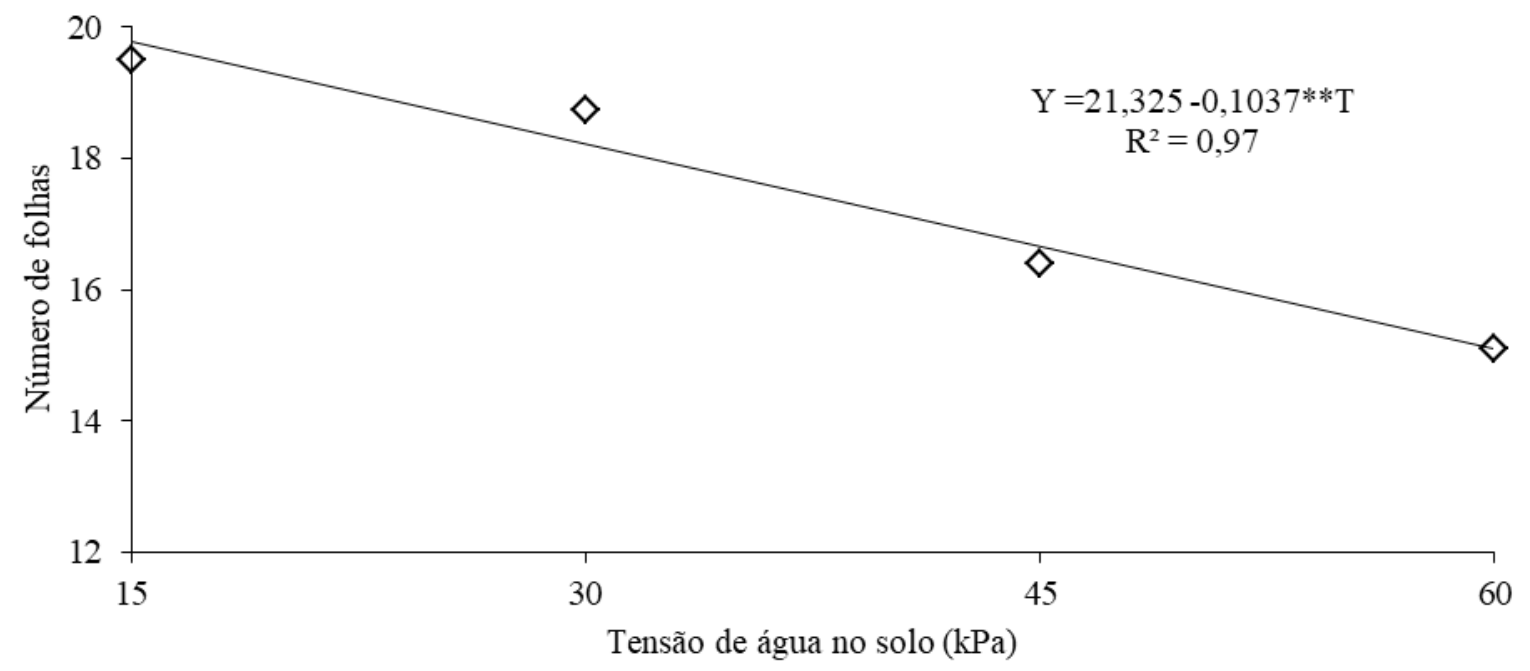


Figura 3. Efeito isolado da tensão de água no solo no número de folhas de plantas de alface Rafaela em resposta a tensões de água no solo. ${ }^{* *}$, significativo a $1.0 \%$, pelo teste de regressão.

Independente do nível da adubação nitrogenada, a máxima média de MFTOL foi de 227,23 g planta $^{-1}$, observada na tensão de água no solo de $15 \mathrm{kPa}$ e à medida em que se aumentaram as tensões de água no solo, houve decréscimo na MFTOL de 34,83\%, se comparada à tensão de água no solo de $15 \mathrm{kPa}$ até a tensão de $60 \mathrm{kPa}$ (Figura 4).

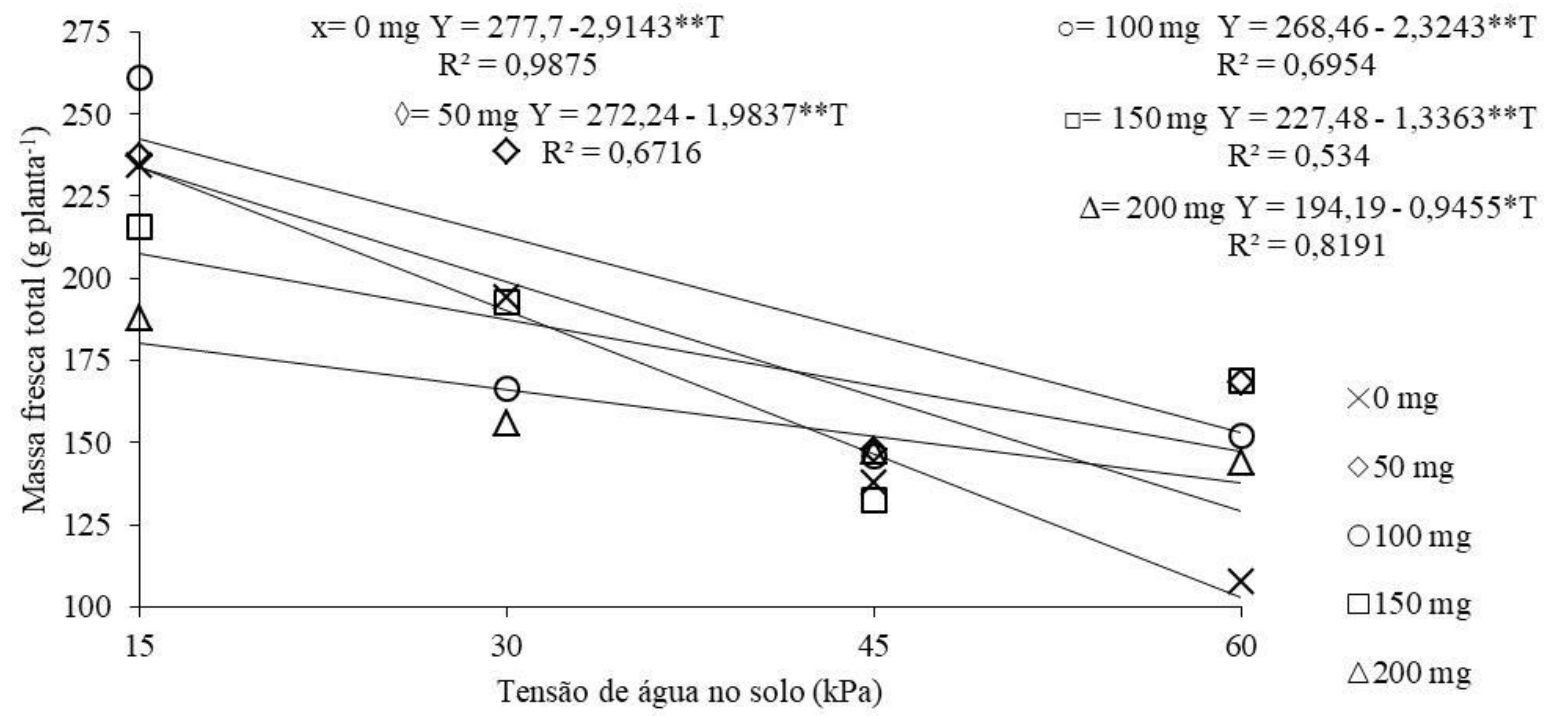

Figura 4. Massa fresca total da alface Rafaela adubada com $0,50,100,150$ e $200 \mathrm{mg} \mathrm{dm}^{-3}$ de nitrogênio e em resposta as tensões de água no solo. ** e *, significativo a 1 e a $5 \%$, respectivamente, pelo teste de regressão.

Beirigo et al. (2010), constataram que a matéria fresca da parte comercial das plantas apresentaram resposta linear inversa com o aumento da tensão de água no solo, a $(\mathrm{p}<0,05)$, sendo que o máximo peso da matéria fresca foi alcançado na tensão de 15 $\mathrm{kPa}$, corroborando com o resultado obtido neste trabalho. Esse resultado deixa evidente a necessidade de fornecer água à cultura em maior frequência, pois na tensão de $15 \mathrm{kPa}$, as irrigações foram aplicadas com maior frequência, porém em menor quantidade, durante cada aplicação. Vilas Boas et al. (2011), trabalhando com tensões que variavam de 15 a $75 \mathrm{kPa}$ na cultura da cebola, também constataram maiores produtividades na tensão de $15 \mathrm{kPa}$, sendo recomendado pelos autores que se adote essa tensão como momento de irrigar.

A massa fresca total apresentou efeito significativo $(\mathrm{p}<0,05)$ quando comparando os níveis de adubação nitrogenada dentro das tensões de 15 e $30 \mathrm{kPa}$, a partir dessa tensão o déficit hídrico foi elevado e dificultou a cultura responder à adubação nitrogenada. Esse resultado pode ser um indicativo de tantas divergências em relação aos resultados obtidos com a aplicação de nitrogênio na cultura da alface, além da disponibilidade hídrica do solo, Nascimento et al. (2017) também atribui essa variação de resultados ao local de cultivo, época de plantio, condições climáticas e o momento em que se realiza a adubação nitrogenada.

A maior massa fresca total $(249,35 \mathrm{~g}$ planta $^{-1}$ ) foi verificada quando se mantém o solo na tensão de $15 \mathrm{kPa}$ e um nível de adubada nitrogenada de $69,47 \mathrm{mg} \mathrm{dm}^{-3}$ (Figura 5). Resultados semelhantes foram encontrados por Amirouche et al. (2019), recomendando uma dose correspondente de $60 \mathrm{mg} \mathrm{dm}^{-3}$ ou $120 \mathrm{~kg} \mathrm{ha}^{-1}$. Esse resultado mostra a baixa exigência da cultura à adubação nitrogenada, sendo que, em excesso aumenta a lixiviação de nitrogênio, onerar o custo de produção e 
Carvalho et al.

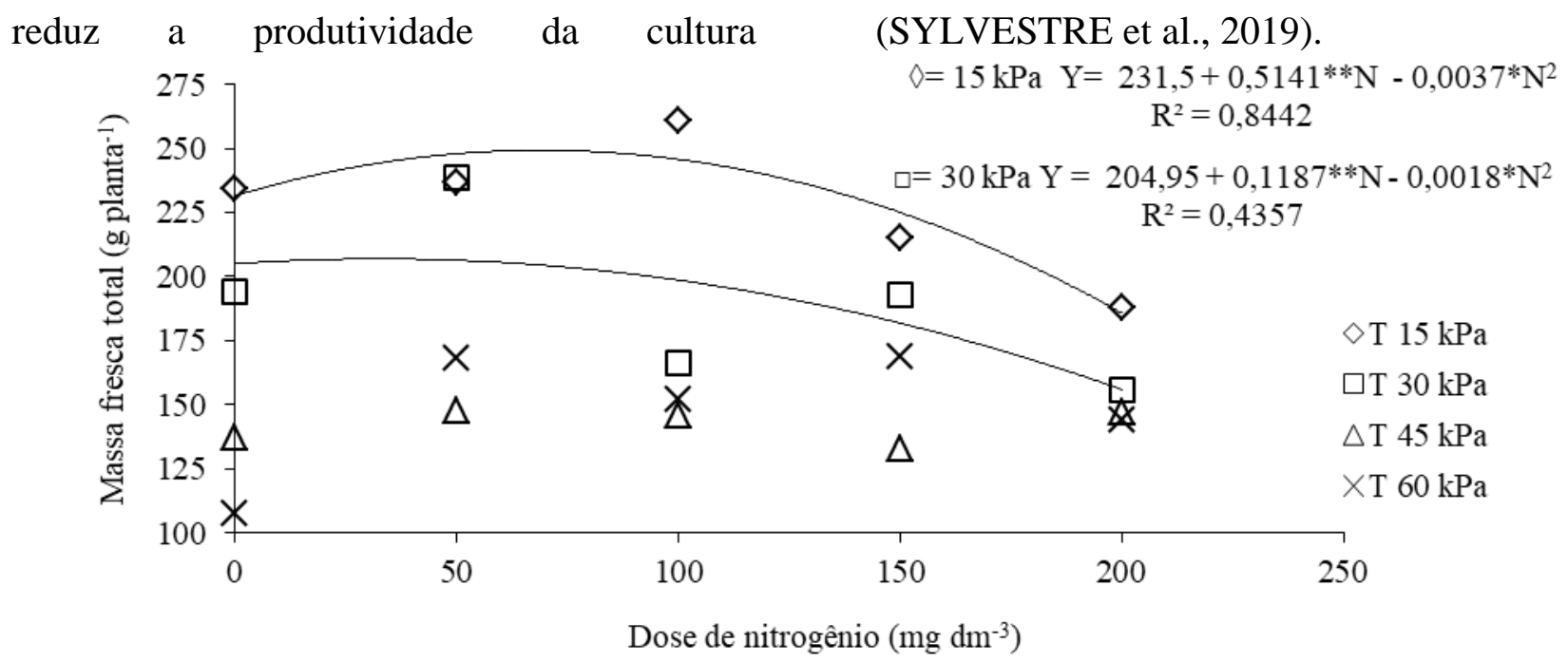

Figura 5. Massa fresca total da alface Rafaela nas tensões de água no solo de 15 e $30 \mathrm{kPa}$ em resposta a adubação nitrogenada. ** e *, significativo a 1 e a $5 \%$, respectivamente, pelo teste de regressão.

Milhomens et al. (2015), verificaram dose semelhante a encontrada no presente estudo, para a máxima produção de massa fresca. Eles também verificaram efeito quadrático da adubação nitrogenada na produção de matéria fresca da parte aérea com a dose correspondente a $75 \mathrm{mg} \mathrm{dm}^{-3}$ de $\mathrm{N}$, para cultivar Verônica.

A AF foi representada por um modelo quadrático de regressão (Figura 6A), obtendose a maior $A F$ na dose de nitrogênio de 84,36

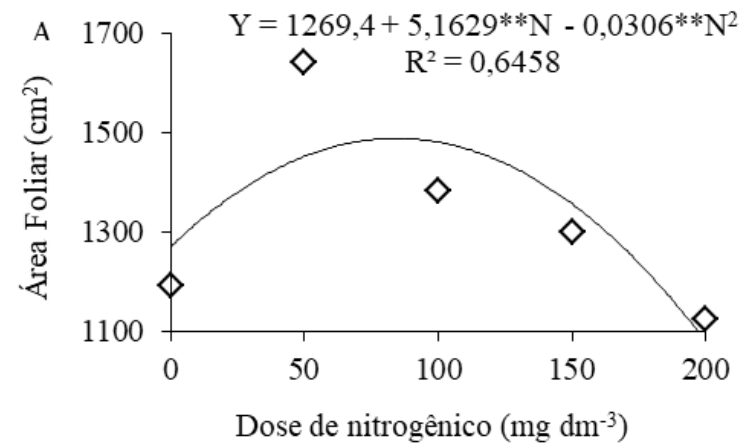

$\mathrm{mg} \mathrm{dm}^{-3}$ e a partir dessa dose, houve um decréscimo de $24,36 \%$, quando comparado a AF obtida nessa dose com a obtida na dose de $200 \mathrm{mg} \mathrm{dm}^{-3}$. Para Mota et al. (2016) o excesso de adubação nitrogenada ocasiona uma série de problemas, como perda de qualidade do produto, redução da área fotossinteticamente ativa e produtividade o que corrobora com este estudo como observado nas Figuras 5, 6A, 6 e 10.

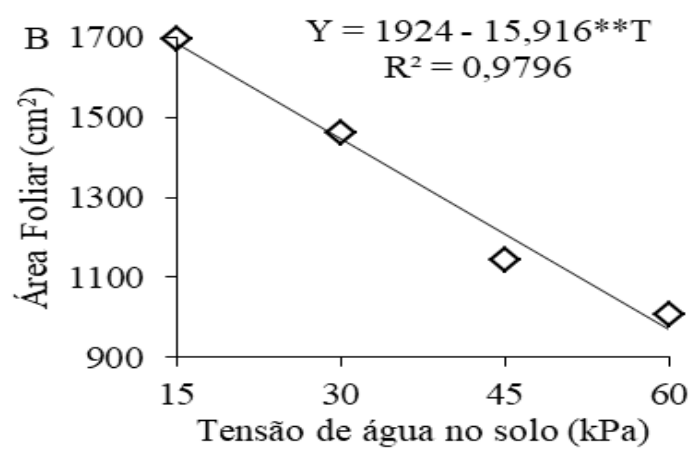

Figura 6. Efeito isolado do nitrogênio e tensão de água no solo na área foliar de plantas da alface Rafaela em resposta a adubação nitrogenada (A) e tensões de água no solo (B). **, significativo a $1 \%$, pelo teste de regressão.

Na medida em que se aumenta a tensão de água no solo, há redução de $\mathrm{AF}$ em alface em 40,66\%, ao comparar à área AF obtida na tensão de $15 \mathrm{kPa}$, com a obtida em $60 \mathrm{kPa}$ (Figura 6B) e reduz também a produção (Figuras 5 e 10). A água é importante para o crescimento da cultura da alface, o ideal é que o solo seja mantido acima de $80 \%$ da capacidade de campo, pois em condições de estresse hídrico, as folhas tendem a se expandir menos do que se estivessem em condições hídricas adequadas (FILGUEIRA, 
2013). Segundo esse autor, quando se tem água mais facilmente disponível para as plantas, elas apresentam maior área foliar e consequentemente, maior transpiração, exigindo assim, maior frequência de irrigação para repor o que foi usado para o metabolismo e liberado para a atmosfera.

Carvalho et al. (2013), estudando as tensões de água no solo $(15,30,45$ e $60 \mathrm{kPa})$ no cultivo do pimentão, constataram menor desempenho produtivo nos tratamentos irrigados a $60 \mathrm{kPa}$, e o aumento na produção nos demais tratamentos foi atribuído à taxa de assimilação total dessa hortaliça, devido ao aumento na $\mathrm{AF}$ e fitomassa da parte aérea. Bilibio et al. (2010), também mostraram que a tensão $15 \mathrm{kPa}$ propiciaram os melhores resultados produtivos para a berinjela, hortaliça também em cultivada em ambiente protegido.

Ao analisar o desdobramento da adubação nitrogenada dentro de cada nível de tensão de água no solo, verifica-se que houve efeito da adubação sobre o desenvolvimento do sistema radicular nas tensões de 15 e 60 $\mathrm{kPa}$ (Figura 7). Na tensão de $60 \mathrm{kPa}$, nota-se que a medida que se aumenta a adubação nitrogenada, reduz-se a MSR. Isso pode ter ocorrido, pois nessa tensão o conteúdo de água no solo era muito baixo e com o incremento da adubação nitrogenada aumentou a sua concentração na solução do solo e assim, contribuindo com o decréscimo no desenvolvimento do sistema radicular.

$\mathrm{Na}$ tensão de $15 \mathrm{kPa}$, verifica-se que a máxima MSR (4,56 g) ocorreu quando se aplicou uma dose de 77,25 $\mathrm{mg} \mathrm{dm}^{-3}$, e a partir de então, ocorreu-se um decréscimo (Figura 7). Essa dose também foi semelhante à verificada para a máxima produção de MFTOL (Figura 5), dose de 69,47 $\mathrm{mg} \mathrm{dm}^{-3}$, máxima AF (Figura 6A), dose de $84,36 \mathrm{mg}$ $\mathrm{dm}^{-3}$ e máxima MSTOL (Figura 9), dose de $68,33 \mathrm{mg} \mathrm{dm}^{-3}$. Este resultado deixa evidente a necessidade de se manter a cultura com um nível de adubação nitrogenada entre 68,33 e $84,36 \mathrm{mg} \mathrm{dm}^{-3}$, para que a cultura apresente seu melhor desempenho agronômico.

Segundo Reichardt e Timm (2004), a umidade do solo influência no transporte de nutrientes que, quando adequada, gera transpiração potencial das plantas arrastando os nutrientes por um fluxo até a superfície radicular. Altos teores de água no solo afetam o crescimento radicular devido a menor aeração do solo; por outro lado, baixos teores de água também causam danos ao desenvolvimento radicular; além disso, o índice de umidade afeta o comportamento mecânico do solo, o que acaba gerando efeitos na penetração das raízes.

Araújo et al. (2011), avaliando o rendimento da alface cv. 'Verônica' cultivada em estufa, em função de doses de nitrogênio aplicadas via fertirrigação, verificaram que a MSR apresentou resposta significativa $(\mathrm{p}<0,01)$, resultando numa equação linear decrescente, obtendo com o tratamento sem adição de nitrogênio o maior valor $(0,639 \mathrm{~g}$ planta $\left.^{-1}\right)$. 
Carvalho et al.

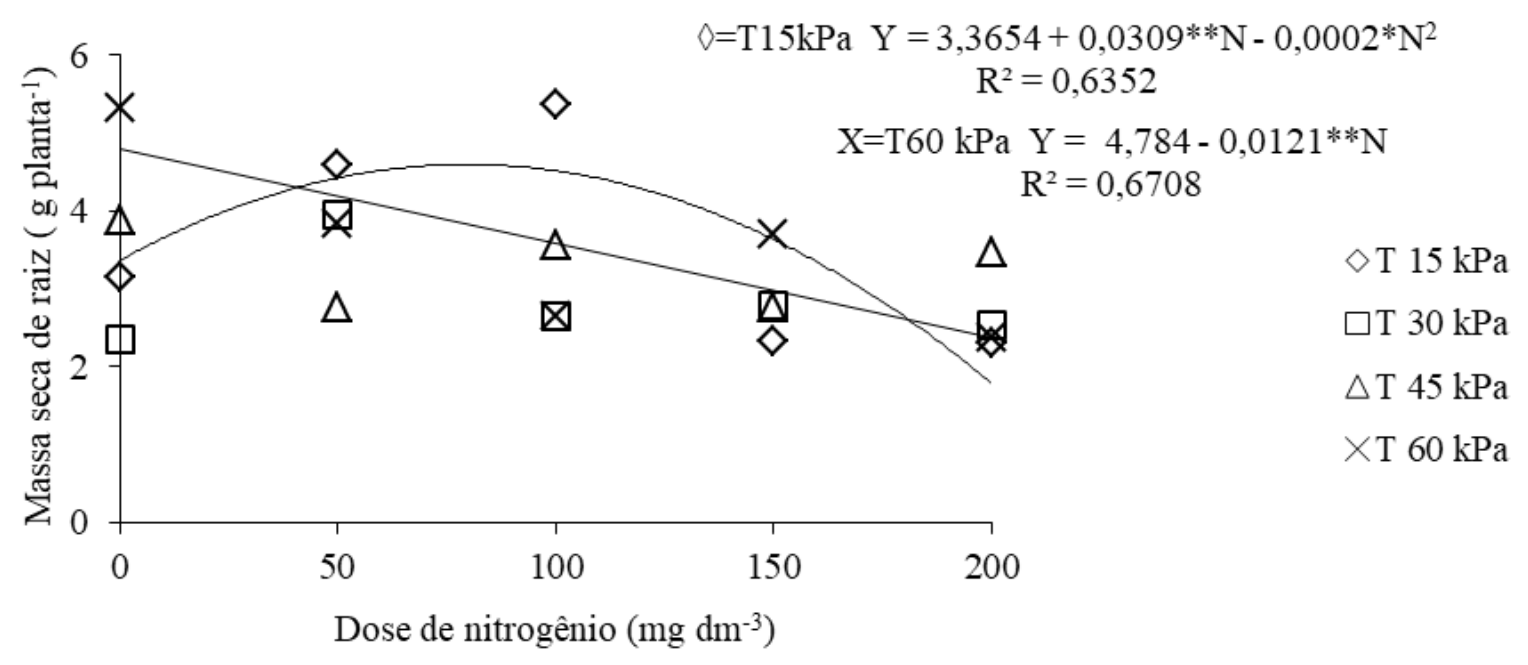

Figura 7. Massa seca de raiz da alface Rafaela nas tensões de água no solo de 15 e $60 \mathrm{kPa}$ em resposta a adubação nitrogenada. $* *$ e $*$, significativo a 1 e a $5 \%$, respectivamente, pelo teste de regressão.

Ao adubar com 50 e $100 \mathrm{mg} \mathrm{dm}^{-3} \mathrm{de}$ nitrogênio, foi observado um decréscimo na produção de massa seca de raiz de 16,34 e $50,65 \%$, respectivamente, com o aumento das tensões de água no solo (Figura 8). Esse decréscimo na produção com a dose de 50 e $100 \mathrm{mg} \mathrm{dm}^{-3}$ de nitrogênio pode ter ocorrido devido a busca pelo nutriente ser pequena, refletindo em pouco desenvolvimento radicular, já nos tratamentos com a ausência de nitrogênio e déficit hídrico as plantas desenvolveram mais o sistema radicular, provavelmente na busca pelo nutriente e por água. $\mathrm{O}$ mesmo comportamento linear decrescente foi encontrado por Vilas Boas et al. (2011) que, avaliando seis tensões da água no solo $(15,25,35,45,60$ e $75 \mathrm{kPa})$, na cultura da cebola e medidas a $0,20 \mathrm{~m}$ de profundidade, constataram que a produtividade de bulbos comerciais apresentou resposta linear decrescente, com o aumento das tensões, sendo alcançado o valor máximo de $47.729,9 \mathrm{~kg} \mathrm{ha}^{-1}$ com a tensão de $15 \mathrm{kPa}$.

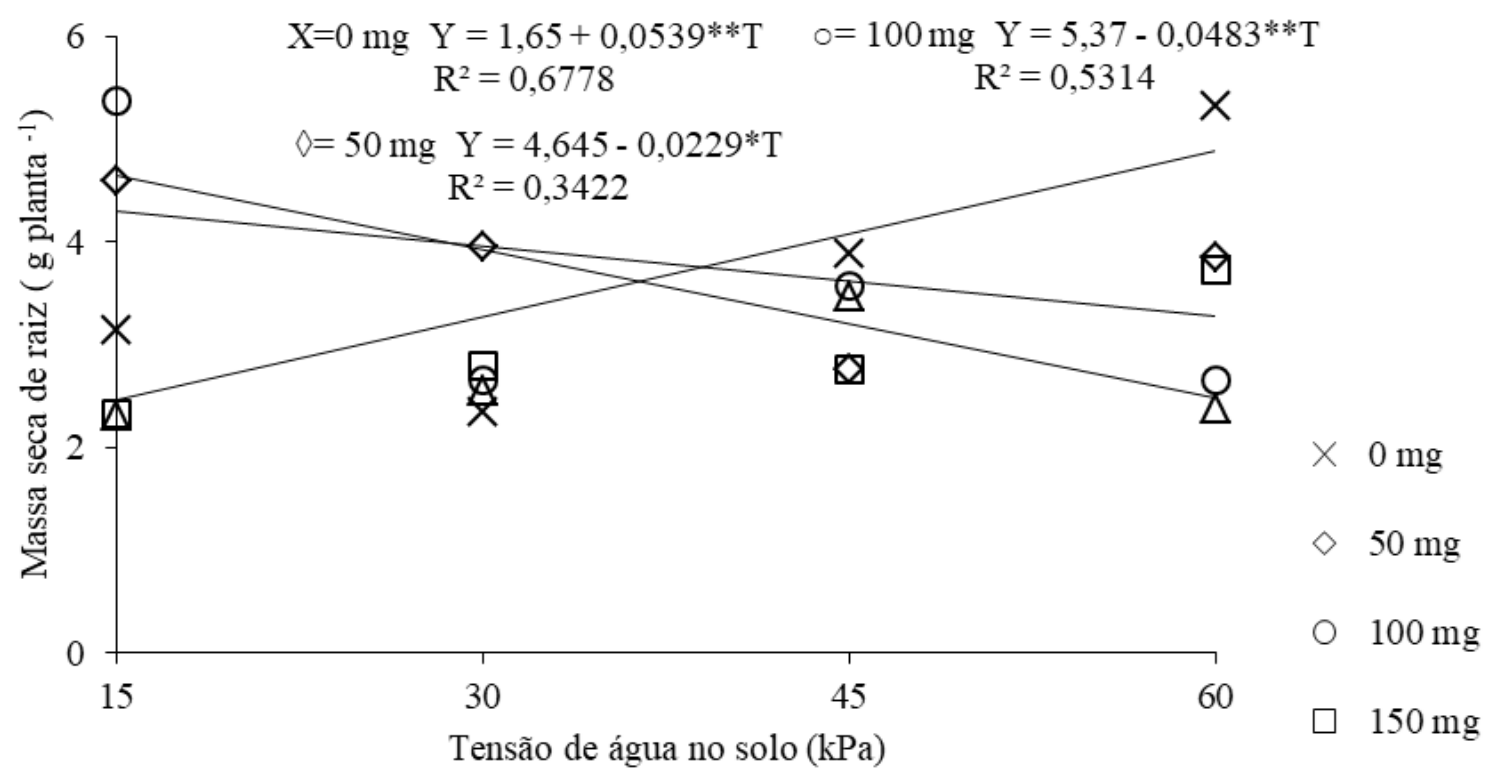


Figura 8. Massa seca de raiz da alface Rafaela adubada com 0,50 e $100 \mathrm{mg} \mathrm{dm}^{-3}$ de nitrogênio e sem adubação nitrogenada em resposta as tensões de água no solo. ${ }^{* *} \mathrm{e} *$, significativo a 1 e a $5 \%$, respectivamente, pelo teste de regressão.

A máxima massa seca total $(16,46 \mathrm{~g})$ foi observada na tensão de $15 \mathrm{kPa}$ e quando adubada com $68,33 \mathrm{mg} \mathrm{dm}^{-3}$ de nitrogênio, o que representa um incremento de $19,81 \%$, se compararmos a ausência de aplicação de nitrogênio com essa dose (Figura 9). Almeida et al. (2011), observaram que com a deficiência de nitrogênio o crescimento das plantas é afetado, esse resultado verificado no trabalho pode ter ocorrido, devido o nitrogênio ser um macronutriente primário essencial, que participar da formação de proteínas, aminoácidos e de outros compostos importantes no metabolismo das plantas. Sua ausência bloqueia a síntese de citocinina, hormônio responsável pelo crescimento das plantas, causando redução do seu tamanho e consequentemente com menor massa seca total (GUARIZ et al., 2012).

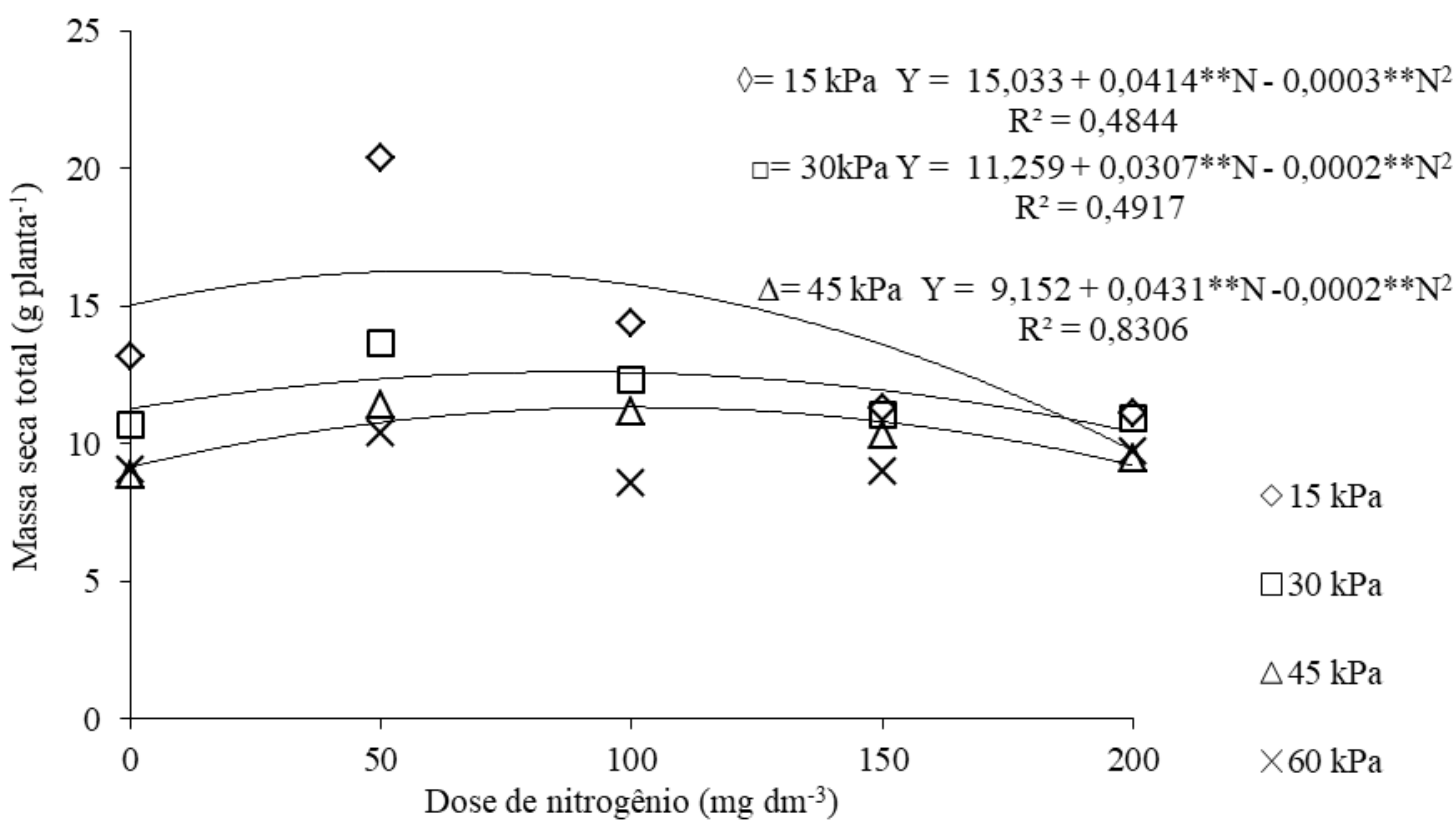

Figura 9. Massa seca total da alface Rafaela nas tensões de água no solo de 15, 30 e $45 \mathrm{kPa}$ em resposta a adubação nitrogenada. **, significativo a $1 \%$, pelo teste de regressão.

A massa seca total da cultura, reduz com o aumento da tensão de água no solo, independente do nível de adubação nitrogenada (Figura 10). Nota-se também que a maior média de produção de massa seca total foi obtida no tratamento de $15 \mathrm{kPa}$ e adubado com $50 \mathrm{mg} \mathrm{dm}^{-3}$, proporcionando uma média de massa seca total de $20,38 \mathrm{~g} \mathrm{planta}^{-1}$, que é
49,17\% maior que a obtida na tensão de 60 kPa e com o mesmo nível de adubação. Esses resultados colabaram os obtidos por Geisenhoff et al. (2016) em que encontraram maior produção de alface americana, quando o solo era irrigado em uma tensão de $12 \mathrm{kPa}$, ou seja, quando o conteúdo de água no solo era mantido próximo a capacidade de campo. 
Carvalho et al.

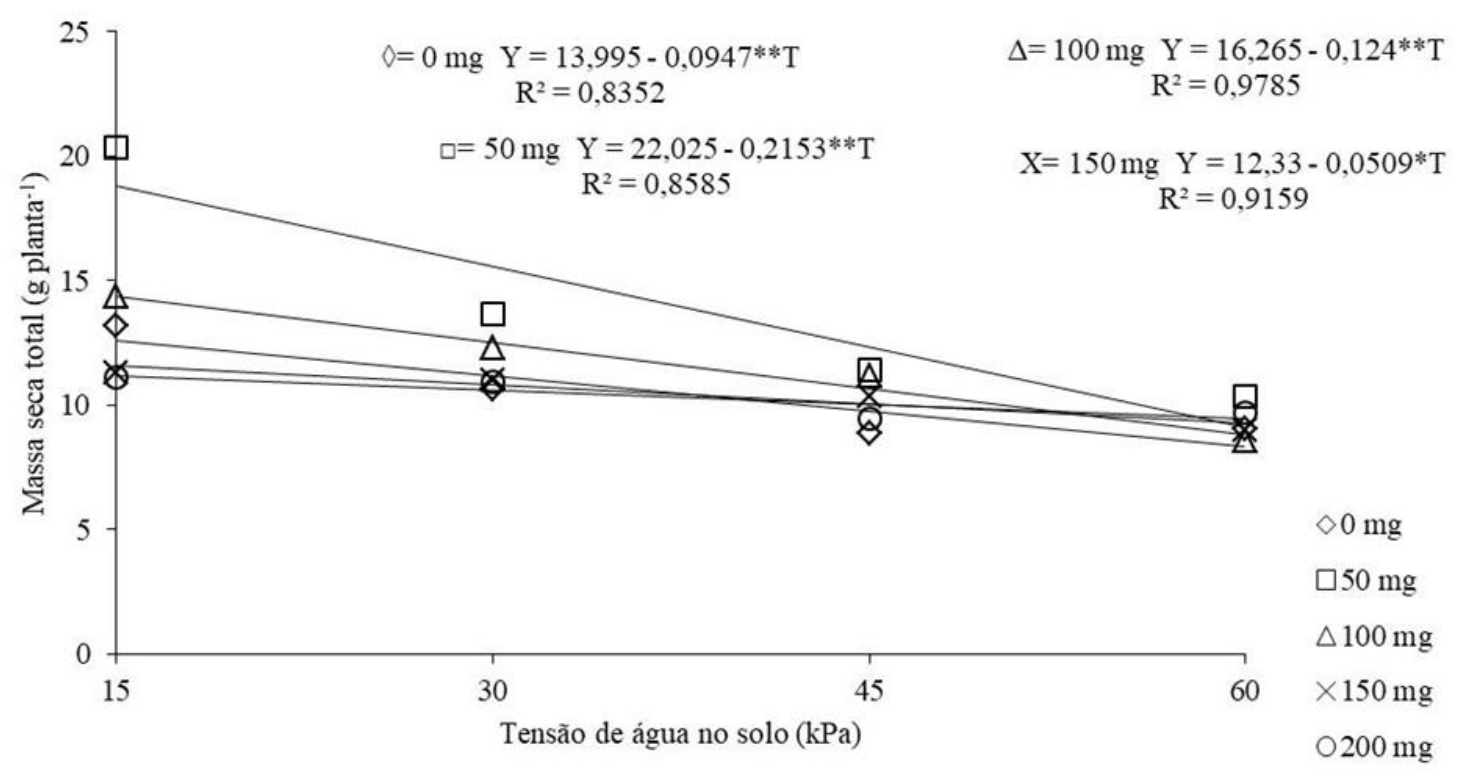

Figura 10. Massa seca total da alface Rafaela adubada com $0,50,100$ e $150 \mathrm{mg} \mathrm{dm}^{-3}$ de nitrogênio e em resposta as tensões de água no solo. ${ }^{*} \mathrm{e}^{*}$, significativo a 1 e a $5 \%$, respectivamente, pelo teste de regressão.

Carvalho et al. (2013), avaliando o efeito de tensões de água no solo $(15,30,45$ e 60 $\mathrm{kPa})$ no desenvolvimento da cultura do pimentão vermelho em condições controladas, também constataram maior massa seca de plantas, na tensão de água no solo de $15 \mathrm{kPa}$. Estes autores também constataram uma tendência de redução na produção de massa seca da parte aérea, a medida que se aumentava as tensões de água no solo e atribuíram-se tais resultados à dificuldade que as plantas de pimentão tiveram em absorver água, pois numa situação de maior tensão, a água fica retida mais fortemente à superfície dos coloides. Dessa forma, as plantas precisam gastar mais energia para adquirir água, para uso em seus processos fisiológicos vitais, fato que afeta negativamente as características de crescimento.

\section{CONCLUSÕES}

A alface americana 'Rafaela' exige para apresentar seu máximo potencial agronômico o intervalo de adubação nitrogenada entre 136,66 e $168,72 \mathrm{~kg} \mathrm{ha}^{-1}$.

Para a obtenção de maior número de folhas, massa fresca da parte aérea total, área foliar, massa seca da parte aérea total e de raiz, o solo deve ser mantido próximo à capacidade de campo, ou seja, deve-se irrigar no momento em que a tensão de água no solo estiver em torno de $15 \mathrm{kPa}$.

A raiz da cultivar Rafaela tem seu desenvolvimento aumentado com a redução da disponibilidade de nitrogênio e maior défice hídrico.

\section{REFERÊNCIAS BIBLIOGRÁFICAS}

ALMEIDA, T. B. F.; PRADO, R. M.; CORREIA, M. A. R.; PUGA, A. P.; BARBOSA, J. C. Avaliação nutricional da alface cultivada em soluções nutritivas suprimidas de macronutrientes. Biotemas, v. 24, n. 2, p.27-36, 2011. Doi: 10.5007/2175$7925.2011 \mathrm{v} 24 \mathrm{n} 2 \mathrm{p} 27$

AMIROUCHE, M.; ZELLA, L.; SMADHI, D. Influence of nitrogen fertilization on lettuce yields (Lactuca sativa L.) using the $15 \mathrm{~N}$ isotope label. v.17, n.3, p.641-652, 2019. https://doi.org/10.15159/AR.19.118

ARAÚJO, W. F.; SOUSA, K. T. S.; ARAÚJO, V. T. V.; DE AZEVEDO, B. M.; BARROS, M. M.; MARCOLINO, E. Resposta da alface a adubação nitrogenada. RevistaAgro@mbiente On-line, v. 5, n. 1, p.12-17, 2011. Doi:10.18227/1982- 
8470ragro.v5i1.440

BEIRIGO, J. D. C.; PEREIRA, U. da C.; SILVA, N. C. da.; CIABOTTI, V. G.; ROCHA, G. B. S.; SANTANA, M. J. de.; OLIVEIRA, S. B. de. Tensão de água no solo para a cultura da alface americana cultivada em Uberaba, MG. In: III Seminário de Iniciação Científica e Tecnológica. 2010, Uberaba. Anais eletrônicos... Uberaba: IFTM, 2010. Disponível em: < http://www.iftriangulo.edu.br/proreitorias/pesq uisa/3o_seminario/trabalhos/agro_tensao_de_ agua_no_solo_alface .pdf $>$. Acesso em: 18 jun. 2018.

BILIBIO, C.; CARVALHO, J. A.; MARTINS, M.; REZENDE, F. C.; FREITAS, E. A.; GOMES, L. A. Desenvolvimento vegetativo e produtivo da berinjela submetida a diferentes tensões de água no solo. Revista Brasileira de Engenharia Agrícola e Ambiental-Agriambi, v.14, n.7, p.730-735, 2010. Doi:10.1590/S141543662010000700007

CARVALHO, J. D. A.; REZENDE, F. C.; AQUINO, R. F.; DE FREITAS, W. A.; OLIVEIRA, E. C. Análise produtiva e econômica do pimentão-vermelho irrigado com diferentes lâminas, cultivado em ambiente protegido. Revista Brasileira de Engenharia Agrícola e Ambiental, v. 15, n.6, p.569-574, 2011. Doi:10.1590/S141543662011000700008

CARVALHO, K. S.; KOETZ, M.; POLIZEL, A. C.; CABRAL, C. E. A. E CRYSTHIAN, R. M. DA S. Cultivo de pimentão vermelho submetido às tensões de água no solo. Enciclopédia Biosfera, v. 9, n. 16, p.659-667, 2013.

DOURADO NETO, D.; NIELSEN, D. R.; HOPMANS J. W.; TEICHARDT, K.; BACCHI, O. O. S. Software to Model Soil Water Retention Curves (SWRC, version 3.0).Scientia Agrícola, v. 57, p. 191-192, 2000 .
FERREIRA, D. F. Sisvar: a computer statistical analysis system. Ciência e Agrotecnologia. v. 35, n. 6, p.1039-1042, 2011. Doi:10.1590/S1413-

70542011000600001

FILGUEIRA, F. A. R. Novo manual de holericultura: cultura e comercialização de hortaliças. UFV. 4 ed. 2013. 421p.

GEISENHOFF, L. O.; PEREIRA， G. M.; LIMA JUNIOR, J. A. D.; SILVA, A. L.; AVIZ, W. L. Greenhouse crisphead lettuce grown with mulching and under different soil water tensions. Engenharia Agrícola, v. 36, n. $1, \quad$ p. $46-54, \quad 2016$. http://dx.doi.org/10.1590/1809-4430-

Eng.Agric.v36n1p46-54/2016

GUARIZ, H. R.; PICOLI, M. H. S.; CAMPANHARO, W. A.; SPERANDIO, H. V. Descrição sintomatológica de deficiência nutricional na mamona durante seu desenvolvimento inicial. Revista Verde de Agroecologia e Desenvolvimento Sustentável, v. 7, n. 2, p. 07-12, 2012.

HUERTA, A. S. Comparación de métodos de laboratório y de campo para el área del cafeto. Cenicafé. v.13, n.1, p.33-42, 1962.

KOETZ, M.; COELHO, G.; COSTA, C. C. C.; LIMA, E. P. E.; SOUZA, R. D. Efeito de doses de potássio e da frequência de irrigação na produção da alface-americana em ambiente protegido. Engenharia Agrícola, v. 26, n. 3, p. 730-737, 2006. Doi:10.1590/S010069162006000300009

MARTINS, C. M; MEDEIROS, J. F; LOPES, W. A. R.; BRAGA D. F.; AMORIM L. B. Curva de absorção de nutrientes em alface hidropônica. Caatinga, v.22, p.123-128, 2009. MILHOMENS, K. K. B; NASCIMENTO, I. R; CASTRO, T. R; FERREIRA, T. A., SOUZA, M. E. Avaliação de características agronômicas de cultivares de alface sob diferentes doses de nitrogênio. Revista Verde 
de Agroecologia e Desenvolvimento Sustentável, v.10, n.1, p.143-148, 2015.

MOTA, J. H.; SILVA, C. C. R.; RESENDE, G. M. Produção de alface americana em função da adubação nitrogenada nas condições de primavera em Jataí-GO. Revista de Agricultura, v. 91, p.156-164, 2016.

NASCIMENTO, M. V.; JUNIOR, R. L. S.; FERNANDES, L. R.; XAVIER, R. C.; BENETT, K. S. S.; SELEGUINI, A.; BENETT, C. G. S. Manejo da adubação nitrogenada nas culturas de alface, repolho e salsa. Journal of Neotropical Agriculture, v. 4, n. 1, p. 65-71, 2017. https://doi.org/10.32404/rean.v4i1.1099

REGO, J. L.; VIANA, T. V. A.; AZEVEDO, B. M.; BASTOS, F. G. C.; GONDIM, R. S. Efeitos de níveis de irrigação sobre a cultura do crisântemo. Revista Ciência Agronômica, v.35, n.2, p.302-308, 2004.

REICHARDT, K.; TIMM, L. C. Solo, planta e atmosfera: Conceitos, processos e aplicações. 1.ed. Barueri: Manole, 2004. 500p.

RESENDE, G.; ALVARENGA M.; YURI J.; DE SOUZA R. Doses de Nitrogénio e Molibdénio no Rendimento e Teor de Micronutrientes em Alface Americana. Horticultura Brasileira. v.28, p.266-270, 2010.

SANTOS, S. R. E.; PEREIRA, G. M. Comportamento da alface tipo americana sob diferentes tensões da água no solo, em ambiente protegido. Engenharia Agrícola, v.24, n.3, p.569-577, 2004. https://doi:10.1590/S01006916200400030000 9.

SYLVESTRE, T. B.; BRAOS, L. B.; BATISTELLA FILHO, F.; CRUZ, M. C. P.; FERREIRA, M. E. M. nitrogen fertilization effects on lettuce crop yield and nitrogen leaching. Scientia Horticulturae, v. 255, p. 153-160, https://doi.org/10.1016/j.scienta.2019.05.032

VAN GENUCHTEN, M. T. A closed-form equation for predicting the hydraulic conductivity of unsaturated soils. Soil science society of America Journal, v.44, n.5, p.892898, 1980.

VILAS BOAS, R. C.; PEREIRA, G. M.; REIS, R. P.; LIMA JUNIOR, J. A. E CONSONI, R. Viabilidade econômica do uso do sistema de irrigação por gotejamento na cultura da cebola. Ciência e agrotecnologia, v. 35, n. 4, p. 781-788, 2011. Doi:10.1590/S1413-70542011000400018. 